\title{
Building the board of directors
}

\author{
For bioentrepreneurs looking to fast-track their company, \\ this is an often overlooked asset.
}

\author{
Jeremy Curnock Cook and Geoffrey Vernon
}

\begin{abstract}
"How strong is the management?" is one of the first questions investors ask when they are reviewing the quality of a company. But it is rare when one hears the question, "What about the board?" In my opinion, not asking this question is all too often a major oversight by both prospective investors and bioentrepreneurs. The board of directors should be a key factor in developing and implementing the right commercial and scientific strategy for a company. What's more, many times it is the board's commitment to realizing this vision over the long haul that fuels the company's success.

Therefore, if you are a bioentrepreneur either contemplating, or actively developing, a biotechnology company, it is important that you understand the function of the board of directors as a key strategic decision-making resource. Moreover, discerning ways in which this resource can be optimized will ensure that the progress of the company keeps pace with present and future shareholder expectations.
\end{abstract}

\section{The board's role}

The role of the board is something that we might be forgiven for thinking requires little discussion. After all, every company has one. Because the structure is very predictable, the roles and responsibilities of the board members appear to be defined as much by tradition as by conscious decision.

But taking a seat on the board requires more than just agreeing to show up at a certain time and place. It requires a dramatic shift in perspective from any other role associated with running a company. Board members are charged with the unique role of placing themselves at a distance from the details of running the company so that they can identify and assess whether the company is moving in the appropriate direction to achieve its goals. In other words, a board member's job is to stay clear of issues about "managing" the business and instead focus completely on issues of "directing" the business.

Quite often, this requires a measure of dis-

Jeremy Curnock Cook and Geoffrey Vernon are directors of Rothschild Asset Management Ltd., Five Arrows House, St. Swithin's Lane, London EC4N 8NR, UK

(geoffrey.vernon@ramasset.co.uk).
Board members are charged with the unique role of placing themselves at a distance from the details of running the company so that they can identify and assess whether the company is moving in the appropriate direction to achieve its goals.

cipline to ensure that the board is meeting to deal with issues at the strategic level, and not being used as a problem-solving resource for issues that should be dealt with by senior and middle management. Often, this process will introduce areas of conflict, particularly for chief executives who have built a company around an area of scientific expertise. The scientific innovator on the board will many times attempt to focus discussion on the technology that is being developed rather than on whether the company is adapting to meet the needs of its customers, pharmaceutical industry collaborators, or investors. The challenge of good corporate management is to ensure the company is meeting these needs, rather than just than the egos of its innovators.

Therefore, a board that is doing its job may be thought of as a company's rudder. It steers the company toward achieving its goals by maintaining a constant focus on its progress from early vision to commercial reality.

\section{Board selection}

One common mistake made by early-stage companies that prevents the board from fulfilling this role is to only recruit board members from a small, familiar circle of associates. This practice tends to create a cozy club rather than a decision-making group that adds real value. The inherent danger of this kind of group is that it nullifies the board's role of critiquing the company's direction. While it is important that the board works as a team, it is equally important that the nonexecutive directors on the board are independent, and can offer constructive criticism.

One reason biotechnology companies often give for recruiting only their associates for the board is their fear that they will lose control of the company. They suggest that the involvement of even one nonexecutive direc- tor on the board will precipitate a power struggle that could wreck the company at an early stage.

My view is that the company with a sound strategic direction has little to fear from its stockholders. One person in isolation cannot force significant decisions on a board. All that a nonexecutive director may precipitate is a "sea change" by presenting a well-supported case, but a reasonable consensus is still required. The greater risk is that an underinformed board will make decisions that will ultimately lead to the failure of the business. The major reason a business falters is that it is allowed to move off course by rapidly burning its capital without achieving critical milestones. Without these milestones under its belt, the company does not create the necessary value to facilitate further fund raising.

In one sense, not allowing truly objective members on the board is only a way of delaying the inevitable. It will then be at the refinancing stage that a significant realignment of both strategy and personnel may have to take place. This trauma, which will result in a costly loss of momentum, could have been prevented by a more sophisticated board that was open to informed debate and able to evaluate different strategic plans objectively.

The lesson here is to welcome at an early stage objective expertise that adds value, hopefully ensuring that wishful or underinformed thinking is challenged prior to all decision making. The reality of progress toward commercialization is that some of the founding management's sacred cows may have to be slain, allowing the company to relinquish activity that is unlikely to increase shareholder value.

\section{Board development}

Frequently, bioentrepreneurs think of a board as a static entity. Nothing could be further from the case. It should be dynamic; the size of the board and the makeup of its members should reflect the development stage of the company. It is, therefore, important to time key board appointments, as they will have a significant impact upon the ability of the company to progress at a rate acceptable to both investors and customers.

For example, during the startup phase, it may be to the company's advantage to form a 
small board of only the most necessary members whose concentration of power can be productive by allowing rapid decision making and rapid development. But as the company develops, the board should also grow in size and diversity as absolute power can become disabling if its goals are not regularly challenged and constructively debated.

Equally problematic, however, is a board that has grown too large. As a rule of thumb, a board that is larger than seven or eight members can become difficult to manage. This can be especially the case if investors are proportionally overrepresented. The principle of involving directors from venture capital companies is clearly correct, but there is a tendency for there to be too many.

For example, a company we recently evaluated had no less than six directors from venture capital firms, most of whom were discussing operational issues at board meetings and neglecting strategic direction. This situation highlights the fact that too few venture capitalists really understand the role of the board.

Gravitating toward operational issues is also indicative of an absence of big-picture thinking, but this tendency can be addressed with appropriate development initiatives. One strategy that we have found effective at the Rothschild Bioscience Unit to encourage strategic thinking of our board members, is to have them attain the diploma in company direction run by the Institute of Directors in London-or a US or Australian equivalent. We also encourage senior management from our investee companies to do the same. These courses help new and prospective board members to add new thinking styles to their portfolio of skills, thus facilitating the transition from "manager" to "director."

Finally, as part of the strategic thinking required to create a board, it is important to plan far in advance. For example, a biotechnology company whose future valuation will be based on the US Food and Drug Administration (Rockville, MD) and European Medicines Evaluation Agency (London) approval of lead compounds should not underestimate the time it may take to identify and recruit a first-class medical director for its board. Since this individual will maximize the probability that compounds will receive approval within the parameters defined by the financing strategy, any delay in their recruitment will cause damaging setbacks in the company's development. Therefore, in board recruitment, as in life, timing is everything.

\section{Board maintenance}

Once your company has assembled a board that reflects its goals, you will find that the process is far from over. Your board, just like other aspects of your company, will require maintenance to assure that it functions effec- tively as a team.

Perhaps the greatest unknown in selecting board members is how well they will work together when facing tough issues. When things do not work out, and the board becomes dysfunctional, there are generally one or more structural reasons that the decision-making team has ceased to share responsibility for continuing in a direction. There are a number of symptoms you can watch out for that will telegraph the likelihood of just this sort of corporate collapse.

Table 1. These signs of a dysfunctional board may spell imminent corporate collapse.

- One-person rule

- A nonparticipating board

- An unbalanced top team

- A lack of management depth

- A weak finance function

- A combined chairperson and chief

executive officer role

The first is the "one-person rule" syndrome. Most often found in a developing company, it is indicative of an isolated director who is attempting to retain control despite lack of support from board members. Here, the power needs to be balanced by diversification or growing the board.

A "nonparticipating board" will emerge when directors cease to work as a team, and start to associate the existence of problems with limited collective consideration of key strategic issues. True participation and collective strategic decision making can only be achieved if the limited time available for board meetings is used effectively, and the chairman should take responsibility for making sure this happens. The chairman's role is therefore critical: He or she should be the "boss of the board," and not merely a figurehead.

An unbalanced top team arises when the board lacks the broad experience required to steer the many facets of a complex company. A common scenario is for power to rest with the individuals who believe they understand areas outside their sphere of experience, and do not see a requirement for recruiting more expertise, or for diluting their influence. They then apply thinking that has its basis in a narrow area to another aspect of the company, but it may be that this thinking does not translate. In a dynamic company that is fusing scientific, financial, clinical, commercial, and operational functions, an unbalanced top team may also neglect the areas outside their comfort zone. Board meetings are essentially a democratic decision process, and without balance, agendas may lack triggers for discussion, while decisions may be made without all the facts.

A lack of management depth is apparent when directors become overinvolved in operational management, limiting their ability to allocate sufficient time to high-level analysis, reflection, and decision making. Typically, the individual fails to be fully effective in either the management or director role.

A weak finance function is caused by the lack of an effective finance director, or by a conflict between finance and other functions. A lack of continuity can be a major contribution to this situation, where the finance director (FD) position is vacated and filled on a regular and damaging basis. This may be indicative of an inability of the CEO to work effectively with the FD and is often interpreted negatively by observers. After all, it is often the FD who is first to know that a business is fundamentally flawed. A finance director comfortable with accountancy but inexperienced in real corporate management is also a significant weakness. Credibility with investors is a prerequisiste for the FD who is able to contribute to the fundraising process.

Finally, be wary of combining the chairperson and CEO role. Even CEOs need to be managed, and it is helpful for contrasting thinking styles to be applied to overall board management.

If your company identifies these symptoms but cannot find a replacement or an additional director for the board within the required time period, the board must be decisive in its determination to bring in expertise from other sources, or to outsource complete functions to service providers with the appropriate capability. The use of outside advisors to supplement internal know-how is therefore of great importance to the growing company, offering a strategic resource and access to expertise which is likely to have already been exposed to similar scenarios.

\section{Conclusions}

The board of directors is an often overlooked key asset of the biotechnology company. The strength of the board's composition should be regarded as a critical success factor that will affect the quality of incoming investment as well as the quality of decision making. But to successfully fulfill this role, board members must set aside operational issues and concentrate on big-picture thinking.

This is especially true as biotechnology startups are increasingly forced to compete in the global arena. A bioentrepreneur needs to know if someone thousands of miles away is pursuing the same scientific goals as his company is in order to gain a competitive advantage. Board members with a global perspective of biotechnology are essential to this process. Not only can they assist in minimizing duplication of effort, but they can add value by helping a biotechnology company to prioritize its functions and goals. 